\title{
The effect of low temperatures on the intermediate and high velocity impact response of CFRPs
}

\author{
J. López-Puente, R. Zaera, C. Navarro* \\ Department of Continuum Mechanics and Structural Analysis, Carlos III University of Madrid, Avda. de la Universidad 30, \\ 28911 Leganés, Madrid, Spain
}

\begin{abstract}
The influence of low temperature on the damage produced on CFRPs by intermediate and high velocity impacts is analyzed. Spherical projectiles were launched against different carbon fiber/epoxy laminates (tape and woven). Experimental tests were done at temperatures ranging from 25 to $-150{ }^{\circ} \mathrm{C}$. The extension of the damage was measured by C-Scan. Results show a clear dependence of damage on temperature, impact velocity and the type of the laminate.
\end{abstract}

Keywords: A. Carbon fibre; Damage

\section{Introduction}

Fiber reinforced plastics (FRPs) are widely used in structural applications. Combination of their different components provides many advantages over conventional metallic materials: high stiffness, high strength and anisotropic behavior that clear the way to optimized designing for specific loading conditions. Among the high performance FRPs, carbon fiber reinforced plastics (CFRPs) are outstanding for their mechanical properties but unfortunately they have very low energy absorption capability when subjected to impulsive loads normal to the laminate plane. Such loading conditions may appear at a widely different velocities: low velocity-that of a dropped tool during assembly or maintenance operations, high velocityimpact of a released blade on the engine casing or projectile impact during flight of a military aircraft or hypervelocityspace debris impacting against a spacecraft. This low energy absorption capacity is mainly due to the brittleness of the epoxy matrix and the low failure strain and shear strength of carbon fibers. To avoid these limitations, engineers try to reduce the impact damage and improve post-damage

\footnotetext{
* Corresponding author. Tel.: +34-91-624-94-91; fax: +34-91-624-9430 .

E-mail addresses: navarro@ing.uc3m.es (C. Navarro), rzaera@ing.uc3m.es (R. Zaera).
}

tolerance by means of matrix toughening [1], fiber toughening [2], hybridizing [3] and through-thickness reinforcement [4]. Different types of impact damage may be found in CFRP laminates: fibre breaking, matrix cracking, matrix crushing, fiber pull-out and delamination, the last being the most ominous in the reduction of the compression, bending and buckling strengths [5] because it produces the separation of the plies and therefore an overall reduction of the laminate stiffness. The type of damage and its extension depend on many factors that have been analyzed by different authors: energy and velocity of the impact [6], laminate stacking sequence and laminate thickness [7] and material properties [8].

Given the excellent stiffness/weight and strength/weight ratios of CFRPs, they are frequently used in the production of structural components for the aeronautical and aerospace industries, applications in which CFRPs may be subjected to low temperatures. In addition, CFRPs are commonly used in the construction of cryogenic tanks on account of their low thermal conductivity and high dimensional stability, so the static properties of carbon fiber composites at cryogenic temperatures have been the subject of several researches. Usami et al. [9] studied the behavior of different epoxy resins at temperatures from -269 to $100{ }^{\circ} \mathrm{C}$, observing that strength increases and failure strain decreases as the temperature falls. Korab et al. [10] and Rogers et al. [11] 
Table 1

Elastic properties of the prepregs (Hexcel)

\begin{tabular}{llllll}
\hline Prepreg & $\begin{array}{l}\text { Thickness/ply } \\
(\mathrm{mm})\end{array}$ & $\begin{array}{l}E_{1} \\
(\mathrm{GPa})\end{array}$ & $\begin{array}{l}E_{2} \\
(\mathrm{GPa})\end{array}$ & $\begin{array}{l}G_{12} \\
(\mathrm{GPa})\end{array}$ & $\nu_{12}$ \\
\hline AS4/3501-6 & 0.175 & 131 & 8 & 3.7 & 0.33 \\
AGP-193-PW/8552 & 0.197 & 68 & 68 & 3 & 0.11 \\
\hline
\end{tabular}

Table 2

Strength properties of the prepregs (Hexcel)

\begin{tabular}{lccclc}
\hline Prepreg & $X_{\mathrm{t}}(\mathrm{MPa})$ & $X_{\mathrm{c}}(\mathrm{MPa})$ & $Y_{\mathrm{t}}(\mathrm{MPa})$ & $Y_{\mathrm{c}}(\mathrm{MPa})$ & $S(\mathrm{MPa})$ \\
\hline AS4/3501-6 & 2105 & 1656 & 74 & 175 & 114 \\
AGP-193-PW/8552 & 795 & 860 & 795 & 860 & 98
\end{tabular}

carried out tests to obtain thermal expansion coefficients for cross-ply, woven, and unidirectional laminates. Giesy [12] described the variation of the laminate strength with temperatures from -269 to $23{ }^{\circ} \mathrm{C}$ and found a slight increase in tension and a small decrease in compression at low temperature as compared with those at room temperature, while Schutz [13] observed an increase in both tensile and compressive strengths. Morino et al. [14] and Aoki et al. [15] analyzed the interlaminar fracture process and showed that matrix cracking is the main problem when CFRPs are considered for cryogenic applications.

The behavior under impact loading at low temperatures has so far received little attention. Dutta et al. [16] analyzed the energy absorption of graphite/epoxy plates under low velocity impact using a Split Hopkinson pressure bar, and found a small dependence on temperature in the range -69 to $20^{\circ} \mathrm{C}$. Kwang-Hee et al. [17] studied the effect of temperature variations $\left(-30\right.$ to $\left.120{ }^{\circ} \mathrm{C}\right)$ on damage to orthotropic CFRP laminates at non-penetrating impact velocities (up to $100 \mathrm{~m} / \mathrm{s}$ ). They observed a linear relationship between the impact energy and the delaminated area, as well as an increase in the damage area as the temperature decreases.

Higher velocities, lower temperatures and other types of reinforcement architectures should also be considered to ensure the structural integrity of CFRP components intended for use in the aforementioned applications. This work examines the effect of low temperature $(-150$ to $25^{\circ} \mathrm{C}$ ) on the extension of the damage produced by intermediate and high velocity impact $(60-520 \mathrm{~m} / \mathrm{s})$ on quasi-isotropic and woven CF/epoxy laminates. C-Scan measurement showed how the damaged area of the composite for a given impact mass and velocity changes with temperature and with the type of laminate.

\section{Impact experiments: projectile and tested materials}

Experimental impact tests on the composite specimens were performed using a tempered steel projectile of $1.73 \mathrm{~g}$ mass. Its shape was spherical in order to avoid scattered results due to changes of the yaw angle, with subsequent modifications of the extension of the damaged area.

Two different laminates were tested to determine the influence of the type of laminate: tape AS4/3501-6 with stacking sequence $[ \pm 45,0,90]_{S}$, and eight layers plain woven AGP-193-PW/8552 (AS4 fiber). These two architectures have been chosen because they are widely used in the aeronautical and aerospace industries. Structural elements subjected to torsion or shear forces are commonly

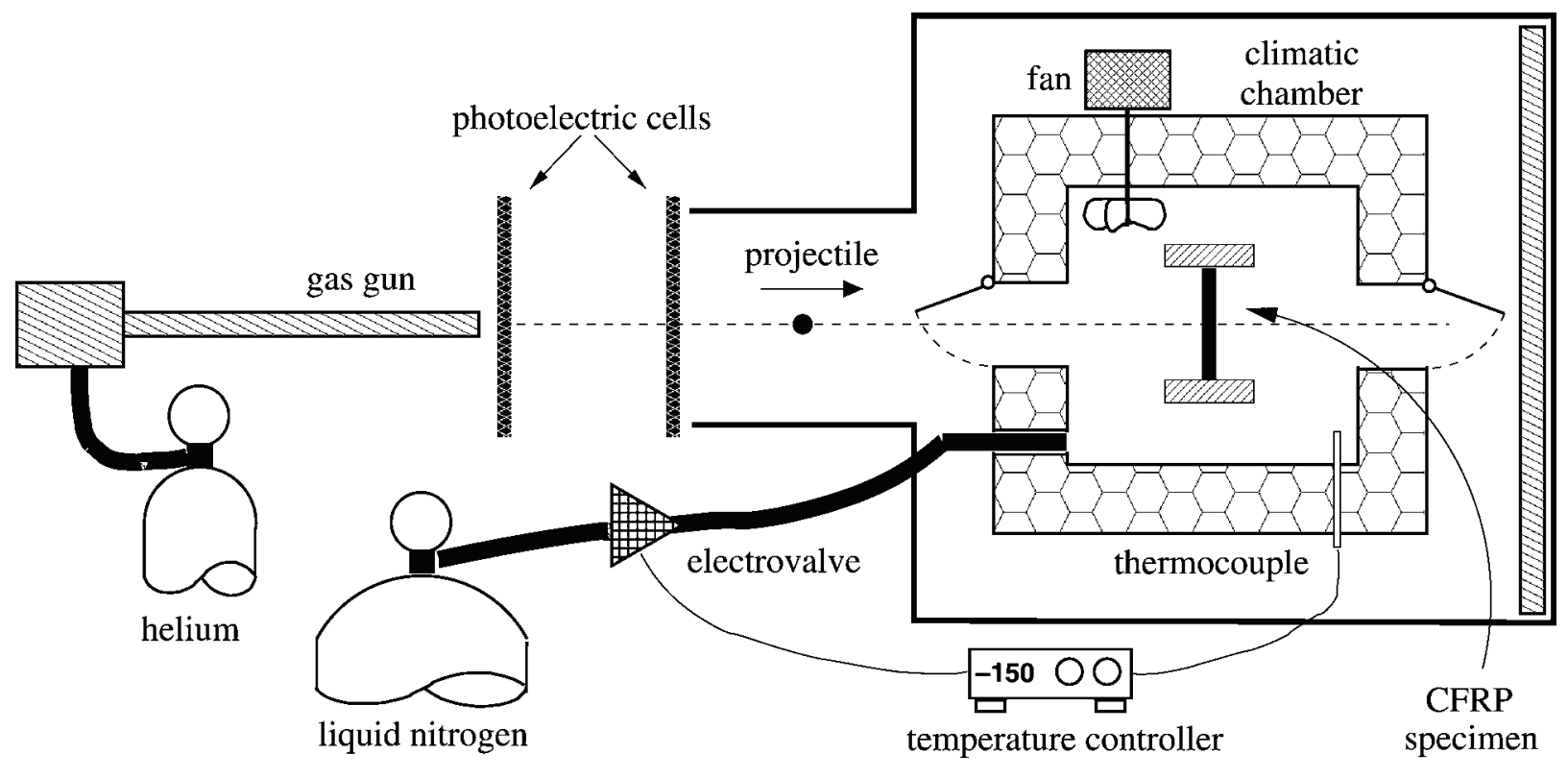

Fig. 1. Sketch of the experimental device: gas gun and climatic chamber inside. 


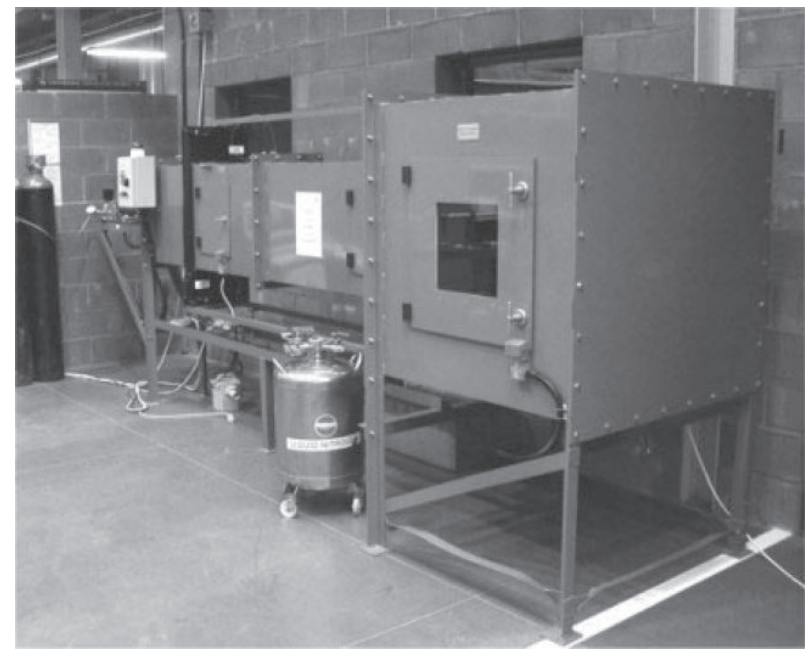

Fig. 2. Experimental device.

manufactured with woven laminates, whereas those subjected to tensile or compressive in-plane loads are manufactured with tape prepregs. The material was provided by SACESA (Spain) from prepregs manufactured by HEXCEL with a volumetric content of fibers of $60 \%$. The elastic and the strength properties of these prepregs are shown in Tables 1 and 2. The specimen size was $80 \times 80 \mathrm{~mm}^{2}$.

\section{Experimental device}

A SABRE gas gun was used to launch the spherical projectile. For the impact test at different temperatures a climatic chamber was specially designed to be coupled to the gas gun. The experimental device is shown in Fig. 1. Fig. 2 shows a photo of the whole device.

\subsection{Gas gun}

The gas gun uses a $7.62 \mathrm{~mm}$ caliber cannon coupled to a helium gas bottle at a pressure of 200 bar. When the exhaust valve opens, the helium impels the spherical projectile at velocities up to $525 \mathrm{~m} / \mathrm{s}$. Once the fragment is expelled from the cannon it travels a distance of $2 \mathrm{~m}$ through a $40 \times 60 \mathrm{~cm}^{2}$ gallery, in which two photoelectric cells detect the passage of projectile to obtain the impact velocity. At the end of the gallery, the projectile reaches an armored box $\left(1 \times 1 \times 1 \mathrm{~m}^{3}\right)$, in which the climatic chamber is located.

\subsection{Climatic chamber}

Since the goal of this study was to carry out low temperature tests, a cryogenic chamber (Fig. 3) was designed and manufactured to provide the thermal conditions. Liquid nitrogen flows inside the chamber, regulated
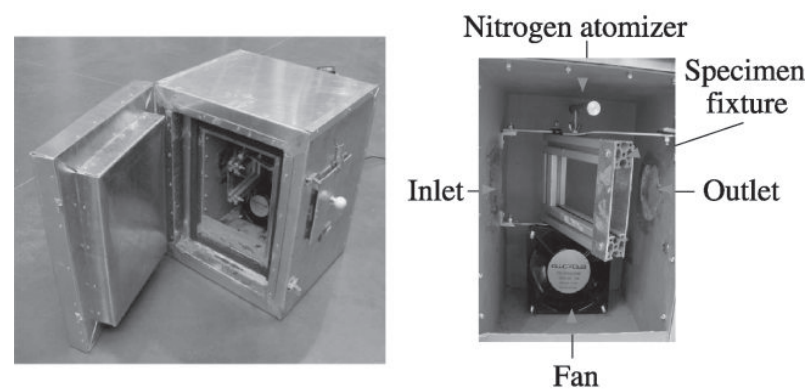

Fig. 3. Climatic chamber.

by an electrovalve, which is controlled by a thermocouple placed close to the composite specimen. A fan ensured that the inner atmosphere was in constant recirculation, with a uniform distribution of temperatures down to $-150{ }^{\circ} \mathrm{C}$. The CFRP specimen is placed in a special tool that clamps its outer border. To be certain of the temperature homogeneity in the specimen before impact, it is cooled inside the chamber during $20 \mathrm{~min}$ at $-60{ }^{\circ} \mathrm{C}$ or $30 \mathrm{~min}$ at $-150{ }^{\circ} \mathrm{C}$, according to a thermal analysis previously performed.

\section{Results}

The impact tests were run at velocities ranging from 60 to $525 \mathrm{~m} / \mathrm{s}$ and at three temperatures $\left(25,-60\right.$ and $\left.-150{ }^{\circ} \mathrm{C}\right)$. After the tests, specimens were inspected by $\mathrm{C}$-Scan to measure the damaged area, and cross-sections of the impacted laminates were examined by optical microscopy to analyze damage patterns. The results are summarized below.

\subsection{Woven laminates}

After the impact test, it was observed that the damage area was not very large in this kind of laminate. This is because the laminate has the fibers oriented in the same direction in each ply. Most experimental evidence has shown that delamination occurs mainly between plies with different fiber orientation [5] and hence a different bending behavior of the plies.

Fig. 4 shows the images obtained by C-scanning of the damaged areas around the impacts at different impact velocities and temperatures. The tests were made at velocities above and below the ballistic limit. Perforation cases may be easily identified looking at the hole in the laminate due to the projectile penetration. The attenuation of the ultrasonic signal becomes zero at that zone and thus a white area appears in the laminate. In the most damaged specimens, the delaminated area is less than four times the cross-section area of the projectile.

An image analyzer program was used to measure damage areas from C-Scan images, considering delamination when the signal attenuation was greater than $4 \mathrm{~dB}$. Average values 


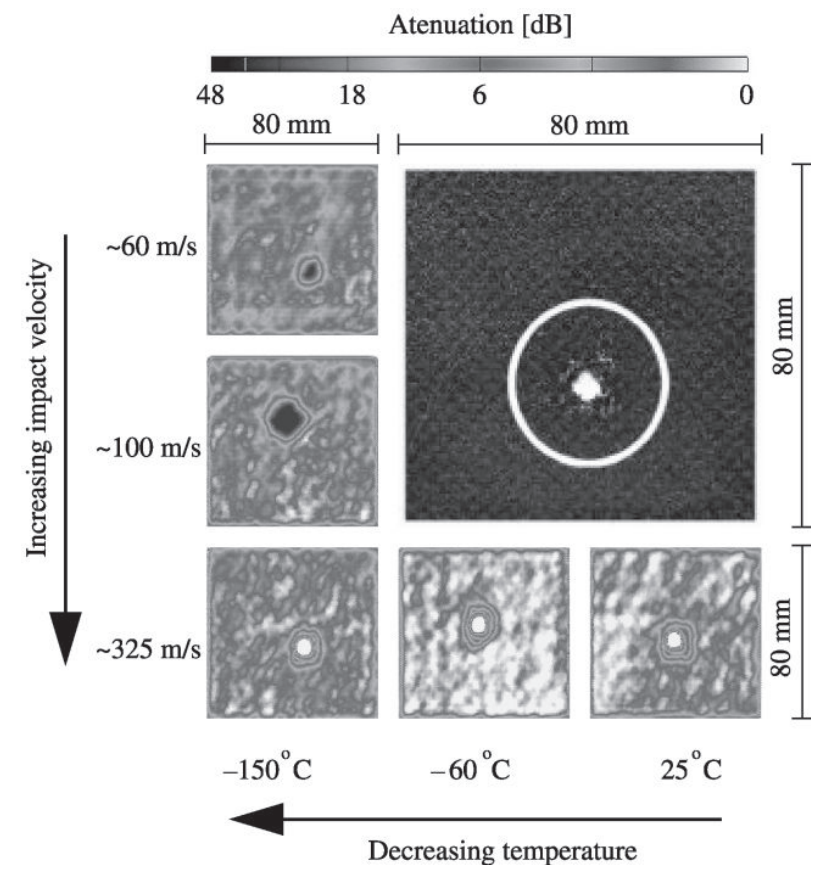

Fig. 4. C-Scan damage contours in woven laminates as a function of impact velocity and temperature. External aspect of the damage in a perforation case.

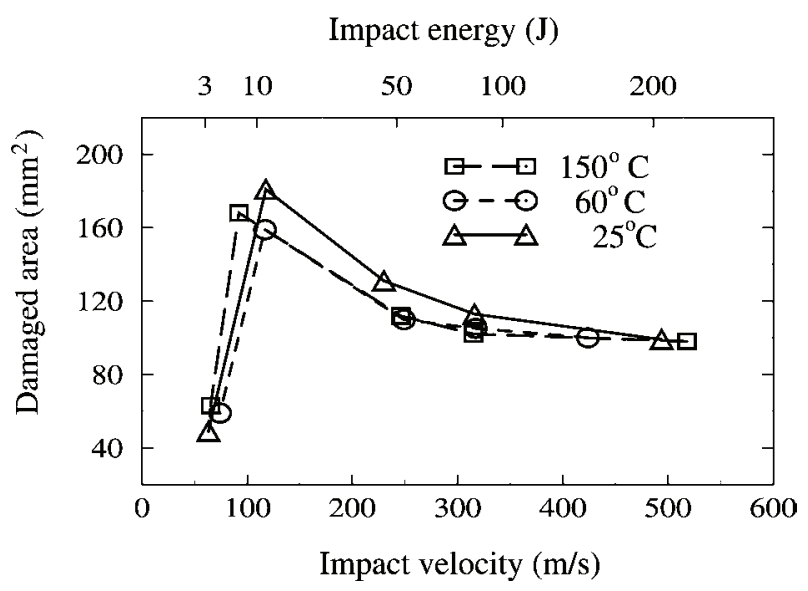

Fig. 5. Damage extension in woven laminates vs impact velocity and energy at three different temperatures.

are plotted in Fig. 5 as a function of the impact velocity at the three temperatures considered. Below the ballistic limit the impact energy is absorbed mainly by local bending of the composite laminate, allowing energy transfer to locations away from the impact zone. Without perforation the impact energy is mainly dissipated by delamination [18]; the higher the kinetic energy the larger the delaminated area. However, above the ballistic limit, the structural laminate response is much more localized around the impact point because loading induces shear plugging with no global bending of the laminate, as is shown in Fig. 6. Damage extension diminishes as impact velocity increases, tending to a limit value and showing a saturation effect. In such conditions the damage area is independent of the impact velocity, and temperature does not significantly affect the damage extension (Fig. 5).

Cross-section images of the tested laminates (Fig. 7) show the damage pattern in this type of laminate, slight damage at low velocity impacts $(60 \mathrm{~m} / \mathrm{s})$ with some delamination on the specimen rear face, due to stress wave reflection (spalling effect). At greater velocities $(100 \mathrm{~m} / \mathrm{s})$ the impact induces in the laminate three different failure mechanisms: shear plugging affecting the first layers, tensile fiber failure on the impact axis, and delamination confined to a conical volume. Above the ballistic limit, mainly shear plugging is observed, with little delamination of the rear face.

\subsection{Quasi-isotropic tape laminates}

Fig. 8 shows images of the damage extension in this kind of laminate, again at impact velocities below and up the ballistic limit. Damage extension becomes about three times greater than that in woven laminates because of the different fiber orientation of each ply.

The effect of impact velocity on damage extension is similar to that in woven laminates, but the temperature has a much greater influence (Fig. 9). Damage extension grows significantly at low temperature. Gómez-del Río et al. [19] studied the dynamic bending behavior of the two laminate types considered. At low temperature the behavior of quasiisotropic CFRP laminates was much more brittle than in woven laminates. The temperature does not affect the mechanical response of the laminate at higher velocities, due to the prevalence of inertial effects (Fig. 9).

Cross-section images of the tested laminates (Fig. 10) show the damage pattern in relation to temperature and impact velocity. Below the ballistic limit, matrix cracking and delamination are the modes of failure, and temperature significantly affects the damage extension. Above this limit, shear plugging of all the layers and delamination of the rear face.
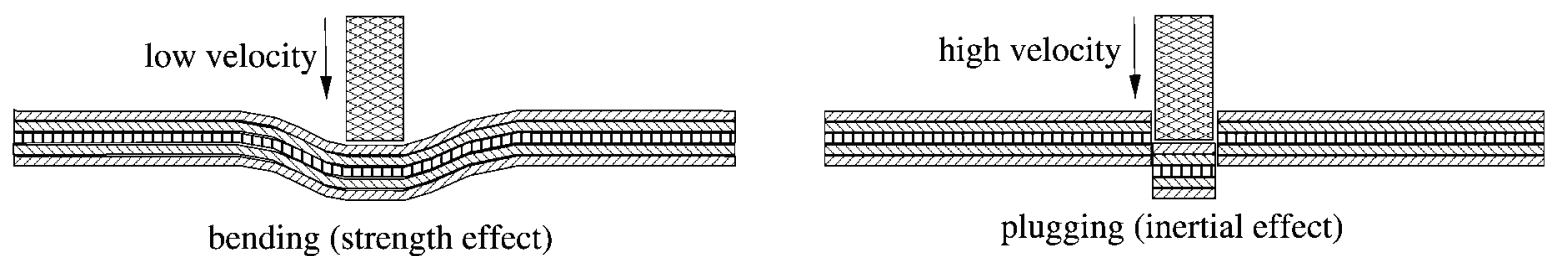

Fig. 6. Effect of velocity on the response of laminates. 


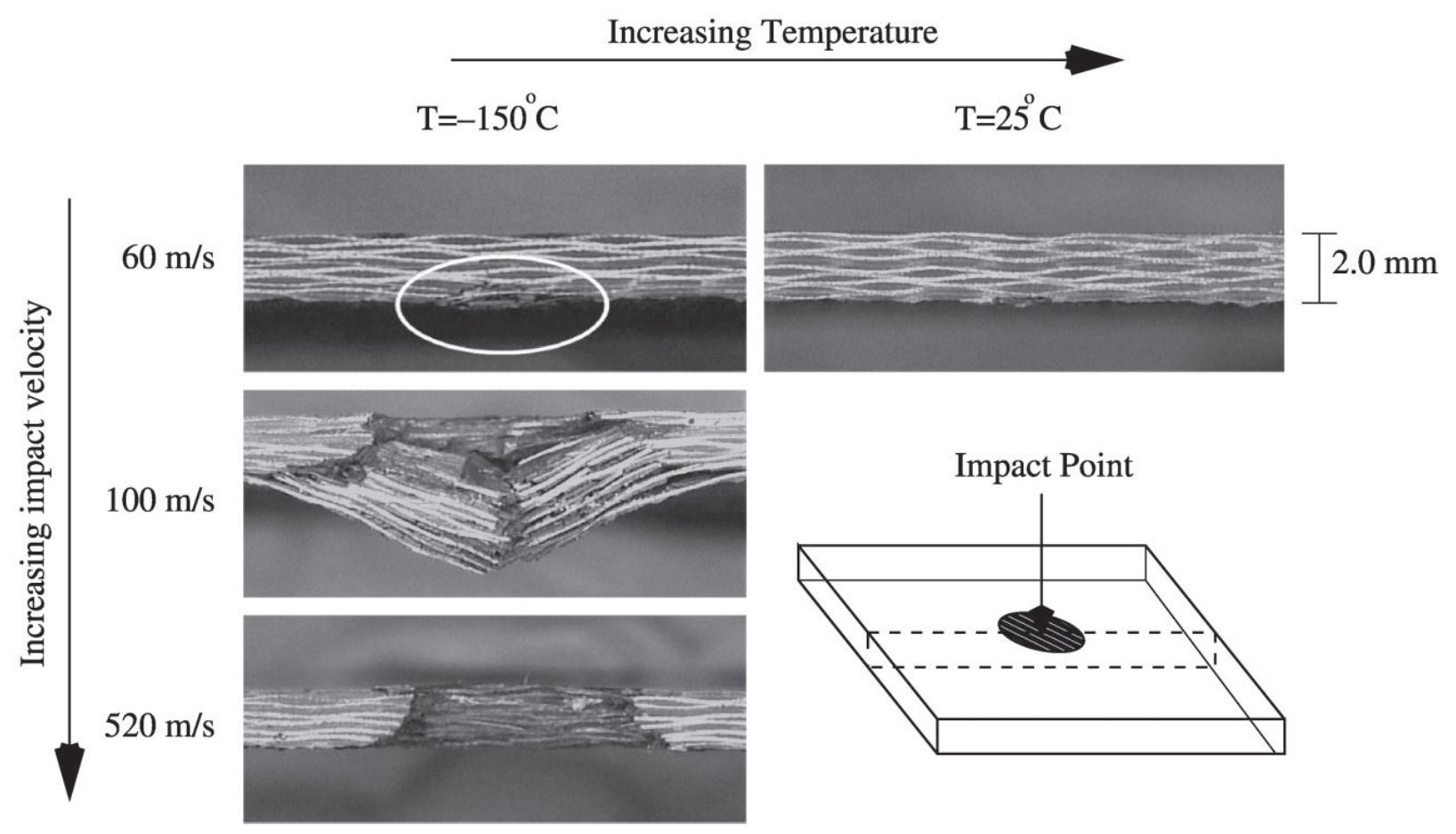

Fig. 7. Cross-sections of woven laminates at different impact velocities and temperatures.

\subsubsection{Effect of thermal stresses}

To analyze the damage increment at low temperature for the quasi-isotropic laminate, thermal stresses were calculated by numerical simulation. In this type of laminate, important thermal stresses appear at low

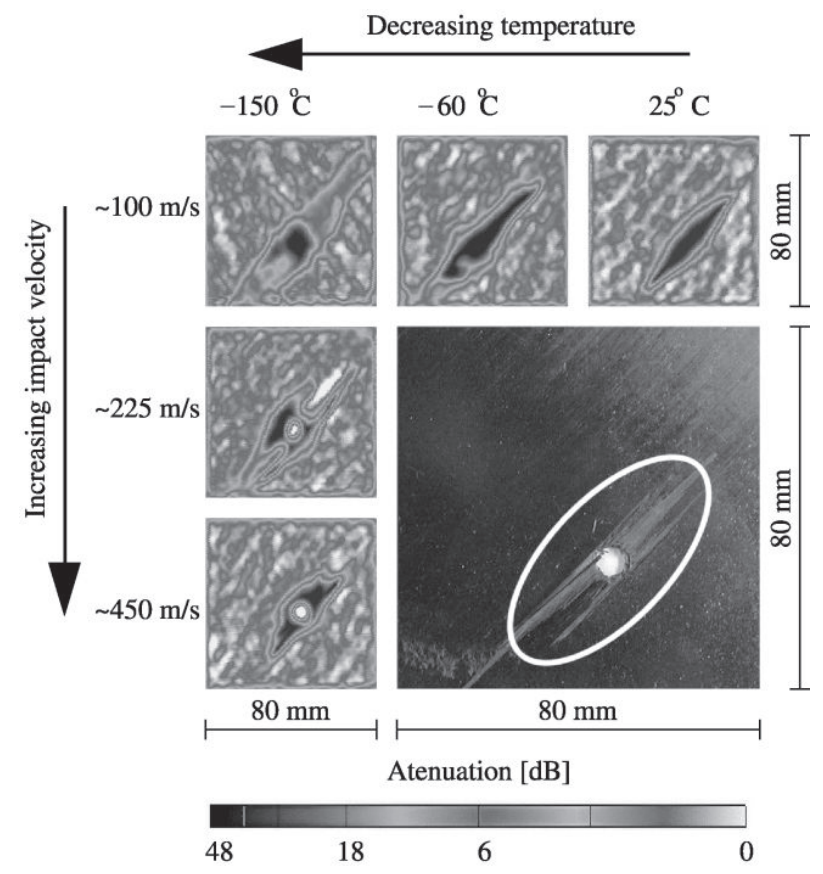

Fig. 8. C-Scan damage contours in quasi-isotropic laminates as a function of impact velocity and temperature. External aspect of the damage in a perforation case. temperature due to the difference between the thermal expansion coefficients of each ply [20]. This effect is not important in woven laminates because the thermal strains are equal for every layer in both in-plane directions. To determine the influence of these stresses on the damage to the composite, full-numerical simulations were made using the finite element method. Assuming free stress state at the curing temperature $\left(180^{\circ} \mathrm{C}\right)$, thermal stresses at 25 and $-150{ }^{\circ} \mathrm{C}$ were calculated. The variation of the thermal expansion coefficients and the elastic properties with temperature are shown in Fig. 11 (as proposed by several authors $[9,11,15,21])$. From the laminate stress

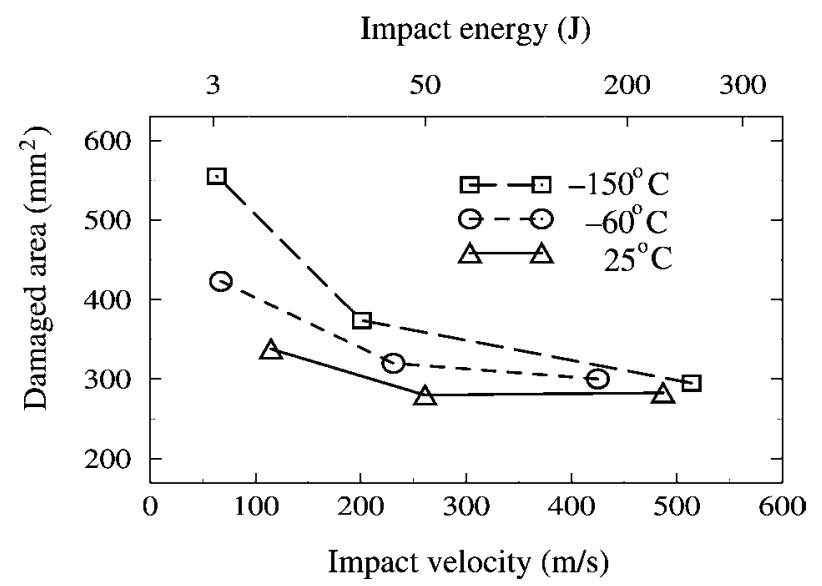

Fig. 9. Damage extension in quasi-isotropic laminates vs impact velocity and energy at three different temperatures. 


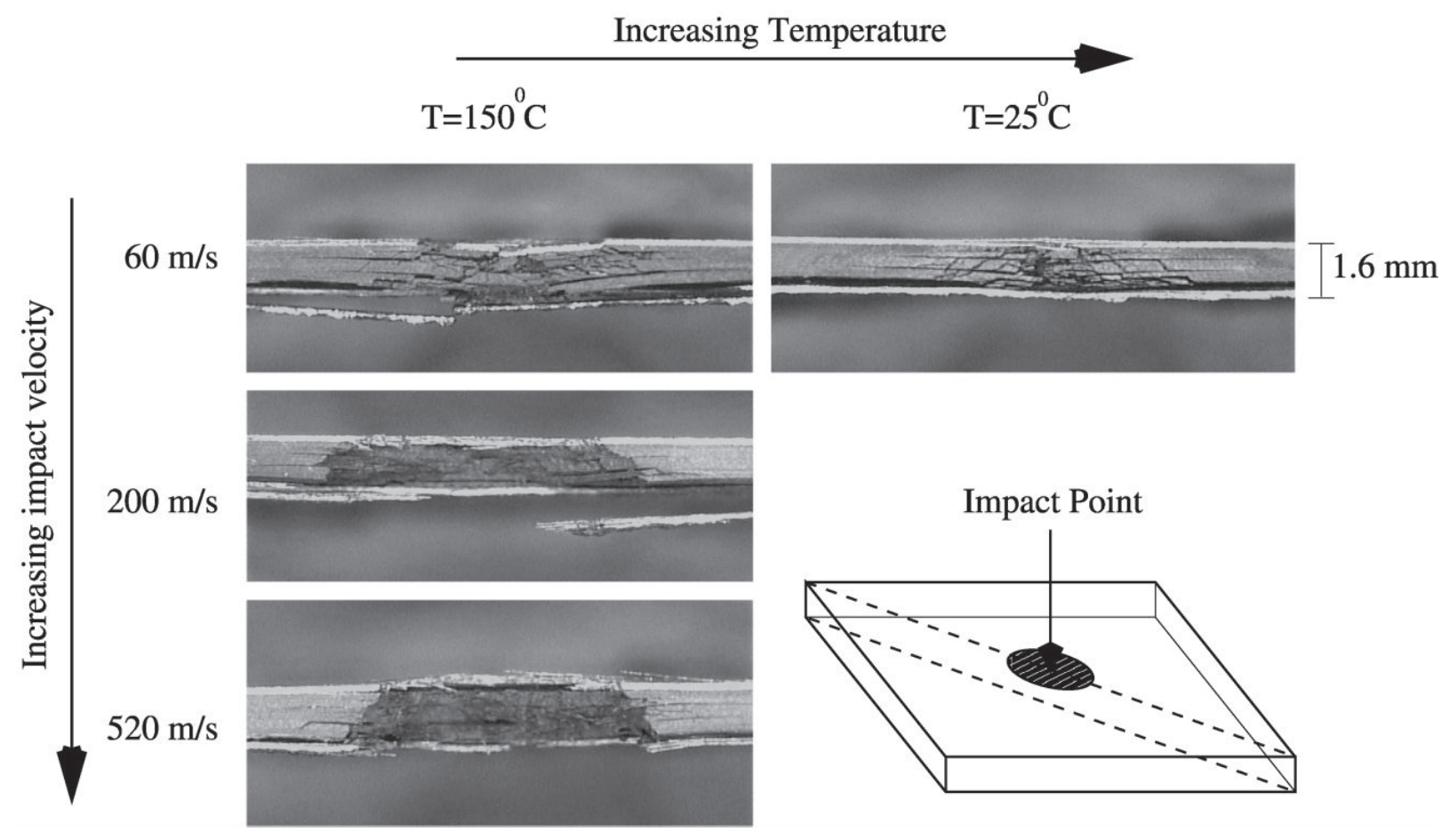

Fig. 10. Cross-sections of quasi-isotropic laminates at different impact velocities and temperatures.

field, contours of the matrix cracking damage parameter $e_{\mathrm{m}}^{2}$ (Eq. (1)) were calculated (Table 3).

$e_{\mathrm{m}}^{2}=\left(\frac{\sigma_{22}}{Y_{\mathrm{T}}}\right)^{2}+\left(\frac{\sigma_{12}}{S_{12}}\right)^{2}+\left(\frac{\sigma_{23}}{S_{\mathrm{m} 23}}\right)^{2} \geq 1$
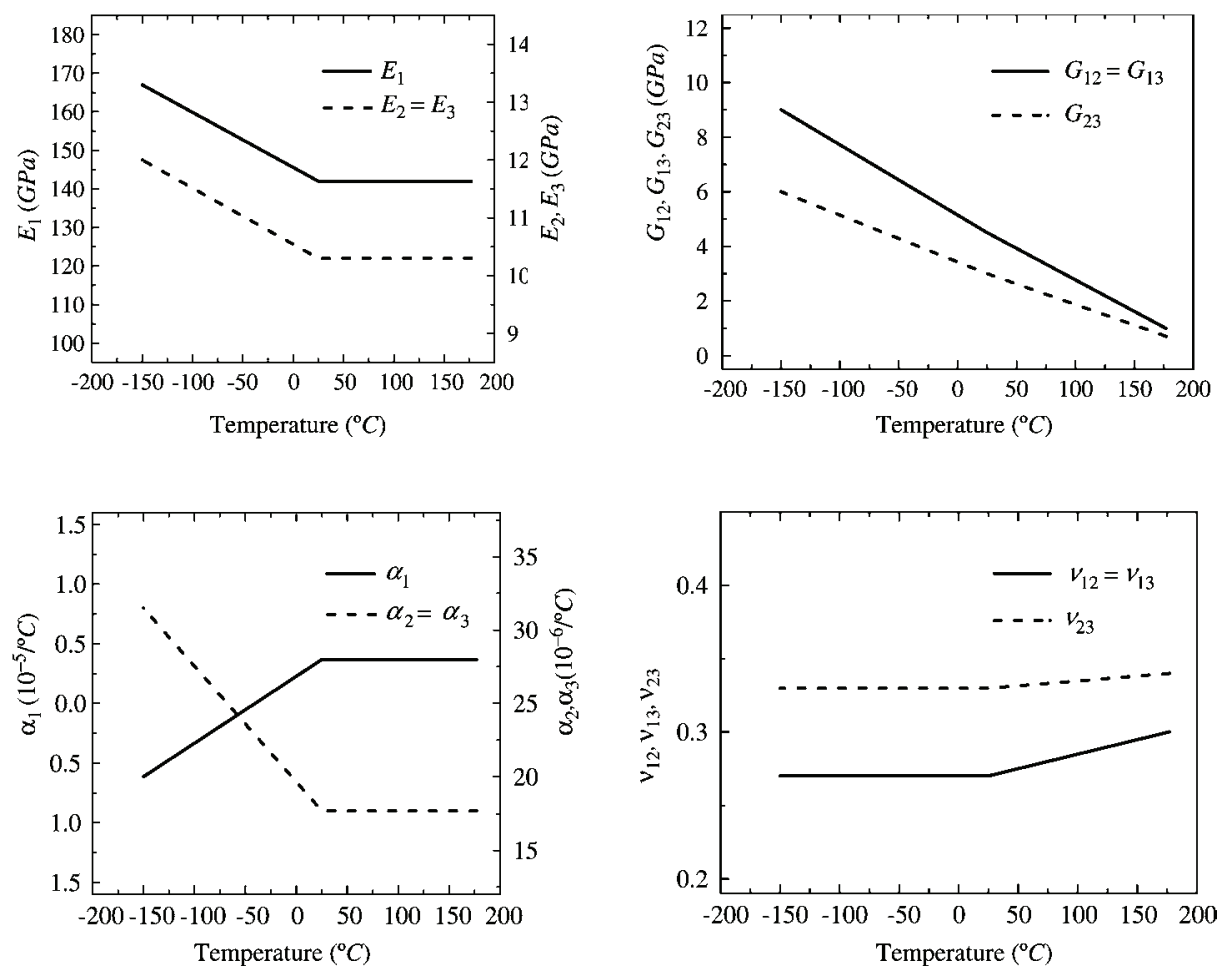

Fig. 11. Evaluation of the laminate elastic and thermal properties with temperature. 
Table 3

AS4/3501-6 properties for $e_{\mathrm{m}}^{2}$ calculation

\begin{tabular}{lll}
\hline Material property & $T=25^{\circ} \mathrm{C}$ & $T=-150{ }^{\circ} \mathrm{C}$ \\
\hline Tensile strength in transverse direction $\left(Y_{\mathrm{T}}\right)$ & $74 \mathrm{MPa}$ & $88 \mathrm{MPa}$ \\
Shear strength for matrix cracking $\left(S_{12}\right)$ & $114 \mathrm{MPa}$ & $136 \mathrm{MPa}$ \\
Shear strength for matrix cracking $\left(S_{\mathrm{m} 23}\right)$ & $64 \mathrm{MPa}$ & $77 \mathrm{MPa}$ \\
\hline
\end{tabular}

matrix cracking in the transverse and through-thickness plane. Table 2 summarizes these failure parameters taken from Refs. [13,21].

It seems that matrix cracks contribute little to energy absorption or reduction of the residual properties. However, before delamination at the ply interfaces, the damage process is initiated by this matrix cracking failure mode. Large differences in contours of $e_{\mathrm{m}}^{2}$ were observed between room and cryogenic temperatures [5]. The magnitude of this parameter at $T=25^{\circ} \mathrm{C}$ is not significant in any ply (about 0.04, Fig. 12) but at $T=-150{ }^{\circ} \mathrm{C}$ it rises to around 0.5 (Fig. 13), and produces a faster damage development on impact.

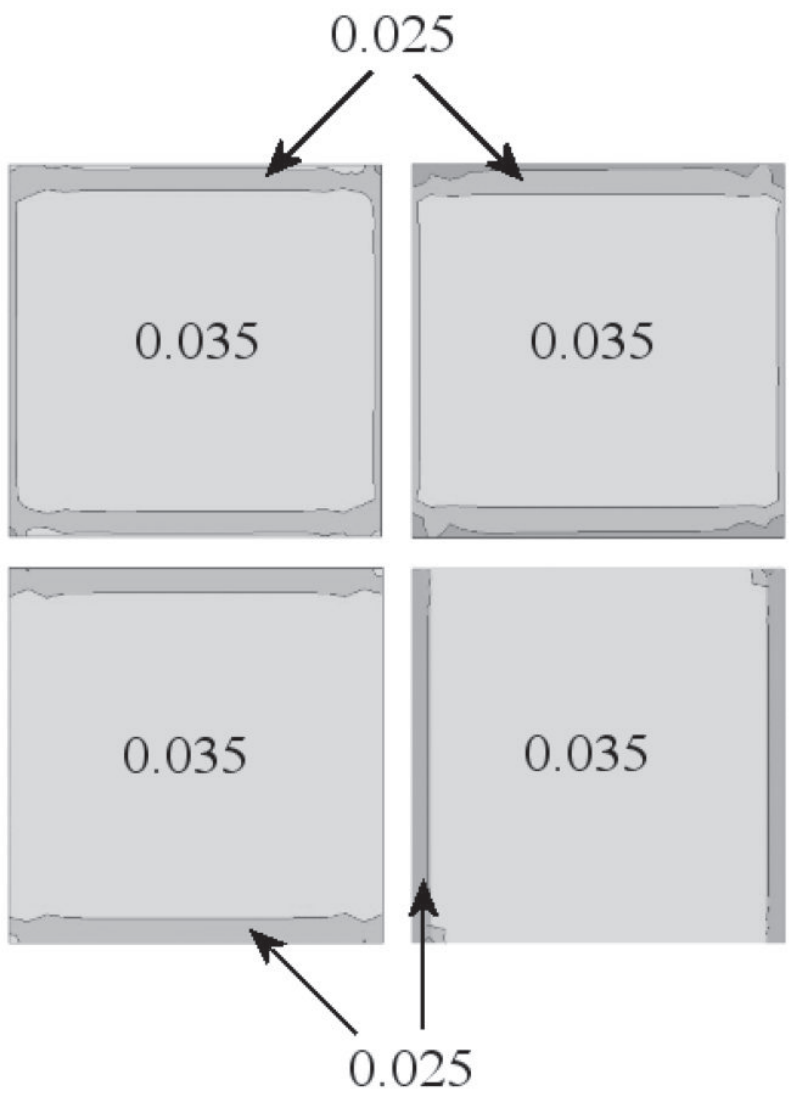

Fig. 12. Values of damage parameter $e_{\mathrm{m}}^{2}$ in quasi-isotropic laminates at $25{ }^{\circ} \mathrm{C}$ due to thermal stresses. Ply +45 (top left), ply -45 (top right), ply 0 (bottom left), ply 90 (bottom right).
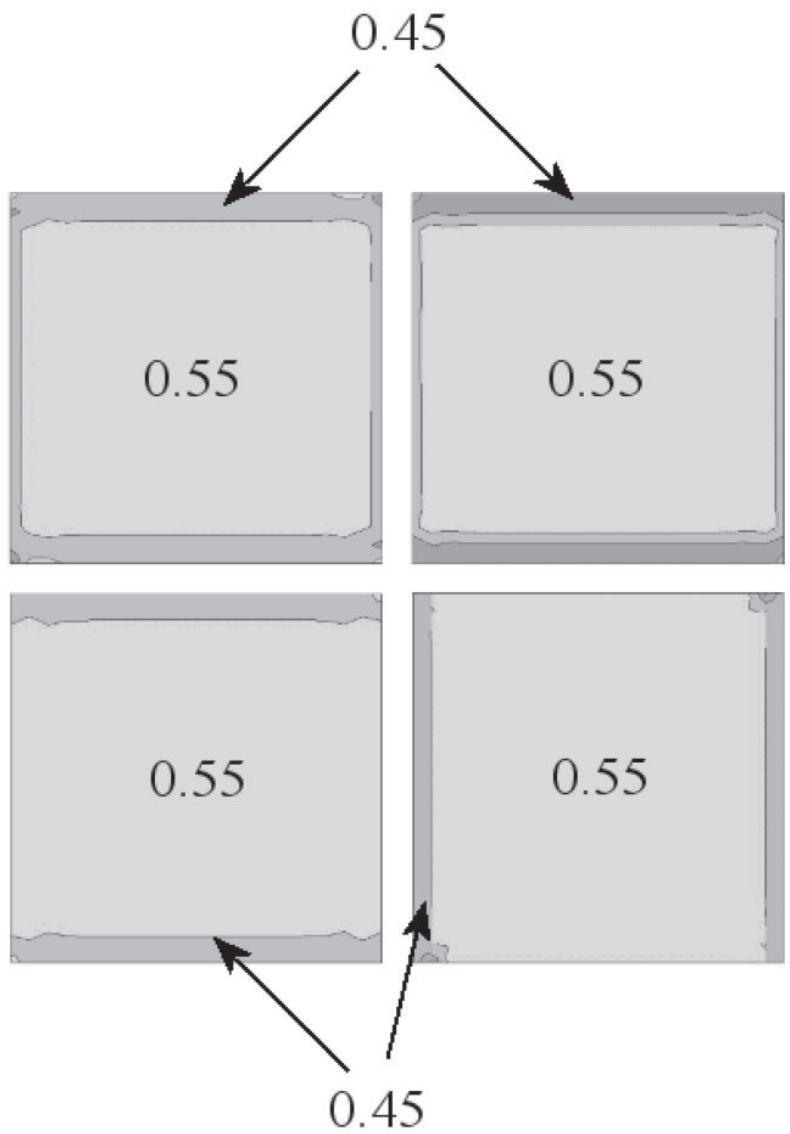

Fig. 13. Values of damage parameter $e_{\mathrm{m}}^{2}$ in quasi-isotropic laminates at $-150{ }^{\circ} \mathrm{C}$ due to thermal stresses. Ply +45 (top left), ply -45 (top right), ply 0 (bottom left), ply 90 (bottom right).

\section{Conclusions}

CFRP laminates are susceptible to damage after impact. Its location is often difficult to detect and it can strongly affect the mechanical properties of structural components, so the study of the parameters that influence the type and extension of damage is of great interest.

The effect of impact velocity and temperature on the mechanical response of CFRP laminates are analyzed here. Quasi-isotropic laminates are less effective against impact than woven laminates, both below and above the ballistic limit, due to the different flexural behavior of its plies. Low temperature affects negatively the impact behavior of the tape laminate, due to the high inplane thermal stresses.

Experimental results showed a damage saturation effect as velocity increases above the ballistic limit; in this velocity range, temperature has no influence on damage extension. For aeronautics and aerospace applications, in which impact velocities can exceed than those considered in this paper, the damage extension could be determined by impact tests at room temperature. 


\section{Acknowledgements}

The authors are indebted to the Comisión Interministerial de Ciencia y Tecnología of Spain for financial support of this work (Project MAT98-0273). They also thank EADSCASA for assistance in C-Scan measurements.

\section{References}

[1] Hedrick JC, Nirajan MP, McGrath JE. Toughening of epoxy resin networks with functionalized engineering thermoplastics. Adv Chem 1993;208:293-304.

[2] Cantwell WJ, Curtis PT, Morton J. An assessment of the impact performance of CFRP reinforced with high-strain carbon fibers. Compos Sci Technol 1986;25:133-48.

[3] Marom G, Drukker E, Weinberg A, Banbaji J. Impact behaviour of carbon/kevlar hybrid composites. Composites 1986;17(2):150-3.

[4] Kang TJ, Lee SH. Effect of stitching on the mechanical and impact properties of woven laminate composite. J Compos Mater 1994; 28(16): $1574-87$.

[5] Abrate S. Impact on composite structures. Cambridge, UK: Cambridge University Press; 1998.

[6] Cantwell WJ, Morton J. Comparison of low and high velocity impact response of CFRP. Composites 1989;20(6):545-51.

[7] Hull D, Shi YB. Damage mechanism characterization in composite damage tolerance investigations. Compos Struct 1993; 23:99-120.

[8] Chen VL, Wu HYT, Yeh HY. A parametric study of residual strength and stiffener for impact damaged composites. Compos Struct 1993; 25:267-75.

[9] Usami S, Ejima H, Suzuki T, Asano K. Cryogenic small-flaw strength and creep deformation of epoxy resins. Cryogenics 1999;39:729-38.

[10] Korab J, Stefanik P, Kavecky S, Sebo P, Korb G. Thermal expansion of cross-ply and woven carbon fibre-copper matrix composites. Composites, Part A 2002;33:133-6.
[11] Rogers KF, Phillips LN, Kingston-Lee M, Yates B, Overy MJ, Sargent JP, McCalla BA. The thermal expansion of carbon fiberreinforced plastics. J Mater Sci 1977;12:718-34.

[12] Giesy RK. Advanced composite materials for cryogenic support structures. ICEC16/ICMC Proceedings, vol. 60, Kitakyushu (Japan); 1996. p. 2053-6.

[13] Schutz JB. Properties of composite materials for cryogenic applications. Cryogenics 1998;38(1):3-12.

[14] Morino Y, Ishikawa T, Aoki T, Kumazawa H, Hayashi Y. Feasibility study of CFRP material application to the cryogenic propellant tank of reusable launch vehicles. Proceeding of 21st International Symposium of Space Technology and Science, Omiya (Japan); 1998.

[15] Aoki T, Ishikawa T, Kumazawa H, Morino Y. Mechanical behavior of cf/polymer composite laminates under cryogenic environment. International Conference on Composite Materials ICCM 12th, Paris (France); 1999.

[16] Dutta PK. Low temperature compressive strength of glass-fiberreinforced polymer composites. J Offshore Mech Arctic Engng 1994; 116:167-72.

[17] Kwang-Hee I, Cheon-Seok C, Sun-Kyu K, In-Young Y. Effects of temperature on impacts damages in CFRP composite laminates. Composites, Part B 2001;32:669-82.

[18] Zee RH, Hsieh CY. Energy loss partitioning during ballistic impact of polymer composites. Polym Compos 1993;14(3):265-71.

[19] del Río TG, Sánchez-Sáez S, Barbero E, Zaera R, López-Puente J, Navarro C. Impact behaviour of CFRPs at cryogenic temperatures. Proceeding of Eighth International Conference on Composites Engineering, Tenerife (Spain); 2001.

[20] Hyer MW. Stress analysis of fiber-reinforced composite materials. Boston: McGraw-Hill; 1998.

[21] Reed RP, Golda M. Cryogenic properties of unidirectional composites. Cryogenics 1994;34(11):909-28.

[22] Hou JP, Petrinic N, Ruiz C, Hallet SR. Prediction of impact damage in composite plates. Compos Sci Technol 2000;60:273-81.

[23] Chang F, Chang KA. A progressive damage model for laminated composites containing stress concentrations. J Compos Mater 1987; 21:834-55. 